\title{
Analytical Application of a Sample Process Control in Detection of Foodborne Viruses
}

\author{
Marta Diez-Valcarce • Nigel Cook • Marta Hernández • \\ David Rodríguez-Lázaro
}

Received: 6 May 2011 / Accepted: 12 June 2011 /Published online: 29 June 2011

(C) The Author(s) 2011. This article is published with open access at Springerlink.com

\begin{abstract}
Sample process controls (SPCs) are an essential component of methods to detect viruses in food, as they verify that the sample treatment has operated correctly. Also, the use of an SPC can allow the efficiency of extraction of the target to be estimated for each individual sample analysed. The use of murine norovirus as SPC is here described. Its efficiency of extraction from different food products was $39.47 \%, 24.79 \%$ and $36.29 \%$ for strawberry, lettuce and shellfish samples. An incorrectly performed sample treatment was modelled to demonstrate the effectiveness of this control.
\end{abstract}

Keywords SPCV. False negatives $\cdot$ Real-time PCR · Food Enteric virus

\section{Introduction}

Enteric viruses are recognised as a main cause of outbreaks and sporadic cases of acute gastroenteritis worldwide (Noda et al. 2008; Scallan et al. 2011; Hall et al. 2005). Thus, detection of the presence of enteric viruses in foods is an important issue in food safety, and rapid and robust

M. Diez-Valcarce $\cdot$ M. Hernández $(\bowtie) \cdot$

D. Rodríguez-Lázaro $(\bowtie)$

Instituto Tecnológico Agrario (ITACyL), Junta de Castilla y León,

Ctra. Burgos, km. 119,

47071 Valladolid, Spain

e-mail: ita-herperma@itacyl.es

e-mail: ita-rodlazda@itacyl.es

N. Cook

Food and Environment Research Agency (FERA),

Sand Hutton,

York, UK diagnostic methodology is needed (Greening and Hewitt 2008; Bosch et al. 2011; Croci et al. 2008). Molecularbased methods have become the typical diagnostic approach for the detection of foodborne viruses (Bosch et al. 2011; Rodríguez-Lázaro et al. 2007). If these methods are to be used for monitoring of food supply chains for viruses, then it is vitally necessary that their analytical results can be reliably verified. Many matrices from the food supply chains most prone to virus contamination-soft fruit, salad vegetable and shellfish - are complex and difficult to treat, and can furthermore contain substances which can inhibit nucleic acid amplification. It is essential therefore that verification includes recognition of analyses where the method has failed to perform correctly, as this may mask the presence of a virus in a sample by a false-negative interpretation of the absence of a signal. Incorrect performance can occur during the sample treatment or the assay, and failed methods can be identified by the use of two controls: a sample process control (SPC) and a nucleic acid amplification control. The principles and use of nucleic acid amplification controls are becoming widely recognised (Hoorfar et al. 2004; Diez-Valcarce et al. 2011; MartínezMartínez et al. 2011; Rodríguez-Lázaro et al. 2004, 2006), but few publications have described the use of an SPC. The incorporation of this control will verify that preamplification sample treatment has functioned correctly, and identify those samples in which pre-amplification sample treatment has failed as well as facilitate the determination of the method's efficiency of detection. In a method for detection of viruses, an SPC is a non-target virus added to every test sample including the negative control sample (or blank) at the start of analysis, and must be detected in every sample into which it has been added (D'Agostino et al. 2011). SPC viruses (SPCVs), must comply with some essential characteristics: they must be 
structurally similar to foodborne viruses of interest, not found naturally in the samples to be tested and preferably have an identical route of infection. As examples, mengo virus $\mathrm{MC}_{0}$ (Costafreda et al. 2006) and feline calicivirus (FCV) and murine norovirus 1 (MNV-1) (Cannon et al. 2006) have been proposed as SPCVs for methods for detection of enteric viruses in food products (Bosch et al. 2011).

The aim of this study was to define the analytical application of a SPCV for nucleic acid amplificationbased methods for detection of enteric viruses in food, and to assess its application to define the efficiency of a pre-nucleic acid amplification sample treatment. Human adenovirus type $2(\mathrm{HAdV}-2)$ was selected as a target enteric virus, as it has been suggested as being useful to indicate that routes of contamination from human sources exist (Wyn-Jones et al. 2011); MNV-1 was selected as SPCV since it possesses a similar molecular and biochemical structure and route of infection to human norovirus (Wobus et al. 2006). It is more acid-tolerant than FCV, and therefore it has been proposed as a more suitable human norovirus surrogate (Cannon et al. 2006).

\section{Materials and Methods}

Viruses and Cell Cultures MNV-1 was propagated in RAW264.7 cells and titrated by end-point dilution (final stock concentration $4.22 \times 10^{6} \mathrm{TCID}_{50} / \mathrm{ml}$ ). HAdV-2 was propagated in A549 cells and titrated by the same technique (final stock concentration $2.1 \times 10^{7} \mathrm{TCID}_{50} / \mathrm{ml}$ ). Total viral RNA or DNA was extracted from infected cultures using QIAamp viral RNA mini kit (QIAGEN, GMBH, Inc., Hilden, Germany), following manufacturer's instructions. MNV-1 was supplied by Prof. Herbert W. Virgin IV, Washington University School of Medicine, USA, according to the MTA signed within the EU project VITAL, and HAdV-2 was supplied by Prof. Rosina Girones, University of Barcelona, Spain.

Extraction of Virus Nucleic Acids from Vegetables and Soft Fruits Ready-to-eat lettuce and strawberries were obtained from a local retail outlet. Approximately $25 \mathrm{~g}$ of sample was placed in a sterile beaker, and approximately $10^{5} \mathrm{TCID}_{50}$ of human adenovirus and $10^{4} \mathrm{TCID}_{50}$ of murine norovirus were added. The protocol described by Dubois et al. (2006) was used to concentrate viruses. Briefly, $40 \mathrm{ml}$ of Tris-glycine $\mathrm{pH} 9.5$ buffer containing 1\% beef extract (TGBE) were added to the sample [in case of soft fruits, 6,500 U of pectinase (e.g. Pectinex ${ }^{\mathrm{TM}}$ Ultra SPL solution, Sigma) were added previously to the TGBE buffer]. Sample was then agitated at room temperature for
$20 \mathrm{~min}$ by rocking at $60 \mathrm{rpm}$. In case of soft fruits, it is crucial to maintain the $\mathrm{pH}$ at 9.0 throughout. The liquid was decanted from the beaker through a strainer into one $50 \mathrm{ml}$ or two smaller centrifuge tubes and centrifuged at $10,000 \times g$ for $30 \mathrm{~min}$ at $4{ }^{\circ} \mathrm{C}$. The supernatant(s) was decanted into a single clean tube or bottle, and the $\mathrm{pH}$ adjusted to 7.2. 0.25 volumes of $50 \%(w / v)$ polyethylene glycol (PEG) 8,000/1.5 M NaCl were then added, and mixed by shaking for $1 \mathrm{~min}$. The suspension was then incubated with gentle rocking at $4{ }^{\circ} \mathrm{C}$ for $60 \mathrm{~min}$, before centrifugation at $10,000 \times g$ for $30 \mathrm{~min}$ at $4{ }^{\circ} \mathrm{C}$. The supernatant was discarded, and the pellet compacted by centrifugation at $10,000 \times g$ for $5 \mathrm{~min}$ at $4{ }^{\circ} \mathrm{C}$ before resuspension in $500 \mu \mathrm{l}$ of PBS. The suspension was then transferred to a chloroform-resistant tube, and $500 \mu \mathrm{l}$ of chloroform: butanol (1:1) was added and mixed by vortexing. The sample was allowed to stand for $5 \mathrm{~min}$ and then centrifuged at $10,000 \times g$ for $15 \mathrm{~min}$ at $4{ }^{\circ} \mathrm{C}$. The aqueous phase was transferred to a clean tube and immediately used for nucleic acid extraction or stored at $-20{ }^{\circ} \mathrm{C}$. Nucleic acids were extracted using a NucliSENS $^{\circledR}$ miniMAG ${ }^{\circledR}$ kit (bioMérieux) according to the manufacturer's instructions. The final elutions were performed with $150 \mu$ l elution buffer (inorganic buffer provided with the kit), resulting in a $300-\mu$ nucleic acid extract. The nucleic acid extract was assayed immediately or stored at $-70{ }^{\circ} \mathrm{C}$.

To demonstrate how the SPCV would indicate extraction failure, the above procedure was performed again, but this time replacing the PEG with an equivalent amount of $\operatorname{Trizma}^{\circledR} \mathrm{HCl}$, to mimic a situation in which a key reagent had been prepared incorrectly [i.e. the buffer $50 \%(w / v)$ polyethylene glycol (PEG) 8,000/1.5 M NaCl was replaced by $50 \%(w / v)$ Trizma $\left.{ }^{\circledR} \mathrm{HCl} / 1.5 \mathrm{M} \mathrm{NaCl}\right]$. In addition, the lysis buffer and one of the washing buffers of the nucleic acid extraction kit (NucliSENS ${ }^{\circledR}$ miniMAG ${ }^{\circledR}$ kit-bioMérieux) were replaced by an equivalent volume of PBS.

Extraction of Virus Nucleic Acids from Shellfish Fresh mussels were obtained from a local retail outlet. Approximately $10^{5}$ TCID $_{50}$ of human adenovirus and $10^{4} \mathrm{TCID}_{50}$ of murine norovirus were added to the digestive gland of one shellfish $(\approx 1 \mathrm{~g})$. The sample was then processed using the method of Henshilwood et al. (2003). The digestive gland was transferred to a clean Petri dish and chopped finely with a razor blade. The chopped gland was then placed into a sterile plastic bag. The digestive gland was weighed then transferred into a centrifuge tube. One millilitre of $3 \mathrm{U} \mathrm{ml}^{-1}$ proteinase $\mathrm{K}$ solution was added and mixed well. The sample was incubated at $37{ }^{\circ} \mathrm{C}$ in a shaking incubator for $60 \mathrm{~min}$, ensuring that the speed setting for the shaker induced 
continual gentle movement of the enzyme/gland mixture. A secondary proteinase $\mathrm{K}$ incubation was carried out by placing the tube in a water bath at $65{ }^{\circ} \mathrm{C}$ for $15 \mathrm{~min}$. The sample was then centrifuged at $3,000 \times g 5 \mathrm{~min}$, and $500 \mu \mathrm{l}$ of supernatant was transferred to a clean microcentrifuge tube and immediately used for nucleic acid extraction or stored at $-20{ }^{\circ} \mathrm{C}$. Nucleic acids were extracted using a NucliSENS ${ }^{\circledR}$ miniMAG ${ }^{\circledR}$ kit (bioMérieux) according to the manufacturer's instructions. The final elutions were performed with $150 \mu \mathrm{l}$ elution buffer (inorganic buffer provided with the kit), resulting in a $300-\mu l$ nucleic acid extract. The nucleic acid extract was assayed immediately or stored at $-70{ }^{\circ} \mathrm{C}$.

To demonstrate how the SPCV would indicate extraction failure, the above procedure was performed again, but this time replacing the proteinase $\mathrm{K}$ solution with the equivalent amount of PBS, to mimic a situation in which a key reagent had been prepared incorrectly. In addition, the lysis buffer and one of the washing buffers of the nucleic acid extraction kit (NucliSENS ${ }^{\circledR}$ miniMAG ${ }^{\circledR}$ bioMérieux) were replaced by an equivalent volume of PBS.

Human Adenovirus Real-Time PCR Assay This assay was a duplex real-time PCR using the primers and conditions described by Hernroth et al. (2002), with the inclusion of an internal amplification control (IAC, Diez-Valcarce et al. 2011) and a carry-over contamination prevention system utilising uracil $N$-glycosylase. The reaction contained $1 \times$ TaqMan Universal PCR Master Mix (Applied Biosystems), $0.9 \mu \mathrm{M}$ each primer, $0.225 \mu \mathrm{M}$ adenovirus TaqMan probe (labelled with FAM), $50 \mathrm{nM}$ IAC probe (labelled with VIC) and 100 copies of adenovirus IAC. Ten microlitres sample of nucleic acid extract was added to make a final reaction volume of $25 \mu$ l. The thermocycling conditions were $10 \mathrm{~min}$ at $95^{\circ} \mathrm{C}$, followed by 45 cycles of $15 \mathrm{~s}$ at $95{ }^{\circ} \mathrm{C}$ and $1 \mathrm{~min}$ at $60^{\circ} \mathrm{C}$.
Murine Norovirus Reverse Transcription Real-Time PCR Assay This assay was a one-step duplex reverse transcription real-time PCR using the primers and conditions described by Baert et al. (2008), with the inclusion of an IAC (Diez-Valcarce et al. 2011). The reaction contained $1 \times$ RNA Ultrasense reaction mix (Invitrogen), $0.2 \mu \mathrm{M}$ each primer, $0.2 \mu \mathrm{M}$ probe MGB-ORF1/ORF2 (labelled with FAM), $50 \mathrm{nM}$ IAC probe (labelled with VIC), $1 \times$ ROX reference dye (Invitrogen), $1 \mu$ RNA Ultrasense enzyme mix (Invitrogen) and 600 copies of murine norovirus IAC. Ten microlitres sample of nucleic acid extract was added to make a final reaction volume of $20 \mu \mathrm{l}$. The thermocycling conditions were $15 \mathrm{~min}$ at $50^{\circ} \mathrm{C}, 2 \mathrm{~min}$ at $95{ }^{\circ} \mathrm{C}$, followed by 40 cycles of $15 \mathrm{~s}$ at $95^{\circ} \mathrm{C}$ and $1 \mathrm{~min}$ at $60^{\circ} \mathrm{C}$.

\section{Results}

Demonstration of SPC Applicability in Detection of Viruses in Foods The results from analysis of the presence of HAdV-2 and MNV-1 in the artificially contaminated foods in which the concentration and nucleic acid extraction protocols were performed both correctly and incorrectly are shown in Table 1. A signal was obtained for both target (HAdV-2) and sample process control (MNV-1) viruses and their IACs from the assays in which the virus nucleic acid extractions from artificially contaminated food products were performed correctly. The average recoveries of the extractions were $39.47 \%, 24.79 \%$, and $36.29 \%$ for artificially contaminated strawberry, lettuce and shellfish, respectively (Table 1). In contrast, no target (HAdV-2) and sample process control (MNV-1) viruses were obtained from the assays in which the virus nucleic acid extractions from artificially contaminated food products were performed incorrectly.

Table 1 Detection of viruses in different food matrices artificially contaminated with HAdV-2 and MNV-1 in which the analytical process was correctly and incorrectly performed

\begin{tabular}{|c|c|c|c|c|c|c|c|}
\hline & & \multicolumn{3}{|c|}{ Human adenovirus (target virus) } & \multicolumn{3}{|c|}{ Murine norovirus (sample process control virus) } \\
\hline & & Strawberry & Lettuce & Mussels & Strawberry & Lettuce & Mussels \\
\hline \multirow{2}{*}{$\begin{array}{l}\text { Correctly } \\
\text { performed }\end{array}$} & $\mathrm{Cp}$ value & $20.07 \pm 0.19^{\mathrm{a}}(9 / 9)^{\mathrm{b}}$ & $20.28 \pm 0.21(9 / 9)$ & $21.55 \pm 0.19(9 / 9)$ & $31.08 \pm 0.22(9 / 9)$ & $31.87 \pm 0.30(9 / 9)$ & $31.23 \pm 0.16(9 / 9)$ \\
\hline & Efficency $^{\mathrm{c}}$ & n.a. & n.a. & n.a. & 39.47 & 24.79 & 36.29 \\
\hline \multirow{2}{*}{$\begin{array}{l}\text { Incorrectly } \\
\text { performed }^{\mathrm{d}}\end{array}$} & Cp value & Undet. $(0 / 9)$ & Undet. $(0 / 9)$ & Undet. $(0 / 9)$ & Undet. (0/9) & Undet. $(0 / 9)$ & Undet. $(0 / 9)$ \\
\hline & Efficency & n.a. & n.a. & n.a. & 0.00 & 0.00 & 0.00 \\
\hline
\end{tabular}

$C p$ crossing point - PCR cycle at which fluorescence intensity rises above background, n.a. not applicable, Undet undetected

${ }^{\mathrm{a}}$ Mean and standard error of $\mathrm{Cp}$ values of three independent nucleic acid amplification reactions using three replicates in each

${ }^{\mathrm{b}}$ Number of positive reactions out of nine reactions

${ }^{\mathrm{c}}$ Percentage of closeness between the results obtained using an artificially contaminated food product and cell culture

${ }^{\mathrm{d}}$ Artificially contaminated samples which were subjected to an incorrectly performed concentration and nucleic acids extraction protocols 
No significant differences $(p<0.05)$ were observed for the IAC signals, which were positive in all the cases (both for the two types of viruses- $\mathrm{HAdV}-2$ and MNV-1 - and the two analytical scenarios-correctly and incorrectly performed). This indicates that the amplification step worked correctly and therefore the lack of signal for HAdV-2 and MNV-1 was due to a mistake during the extraction, which indeed was the experimental scenario planned.

\section{Discussion}

A mandatory step needed for the effective implementation of molecular diagnostics for the detection of enteric viruses in food supply chains is that the reliability of the analytical results can be verified (Rodríguez-Lázaro et al. 2007). Many matrices from the food supply chains like salad vegetable, shellfish and soft fruit are prone to virus contamination. They contain substances which can affect removal of the virus and its subsequent concentration, extraction of virus nucleic acids, and/or inhibit nucleic acid amplification, and therefore it is essential that this verification includes the recognition of failed methods as these may mask the presence of a virus pathogen by a false-negative interpretation of the results (Hoorfar et al. 2004). The use of a sample process control can provide this recognition.

An important aspect of an SPC is that it must be a virus that shares a very similar biochemical and molecular structure to the virus to be tested. This is a critical issue, as the reliable implementation of this control will rely on it being able to mimic the actions that the target virus will make during the analytical procedure.

Finally, it should be demonstrated that a sample process control can identify any problem during the whole analytical procedure. In this study, using three different types of foods, i.e. strawberries, lettuce and shellfish, which have been implicated in several outbreaks of viral disease (Baker et al. 2010; Maunula et al. 2009; Grotto et al. 2004; Ethelberg et al. 2010) and which have often been found to contain inhibitory substances (Croci et al. 2008), the SPC showed that the performance of the molecular-based analytical procedure for enteric viruses could be verified (concentration, nucleic acid extraction and nucleic acid amplification steps). However the use of an IAC in addition to SPC will allow more precise troubleshooting. The principle of an SPCV is that if it is detected, then the method was performed correctly. If it is not detected, the method has failed and the foodstuff must be reanalysed. In addition to this qualitative interpretation of an analytical result, the SPCV also allow a determination of the recovery efficiency for each individual sample, by comparing the (RT-)PCR results of SPC virus before and after addition to the sample. When the SPC virus is a good surrogate of the target virus, its efficiency of extraction will reflect that of the target, and allows a more precise determination of the target virus load in a sample. Thus, if the result of analysis was that 20 genome copies of a target and 40 genome copies of the SPCV are detected in a sample, and 100 genome copies of the SPCV were initially added, it could be inferred that the original number of target genome copies contaminating the sample was around 50, as the efficiency of the recovery for the SPCV was $40 \%$.

In conclusion, this study has demonstrated the application of the inclusion of an SPC for assessing correct performance of the analytical procedure. The SPCV described in this study can be reliably used, and provide a robust control that can be routinely applied in the analysis of foods for viruses.

Acknowledgements This work was supported by the EU VITAL project Contract No. 213178. MD-V received a Ph.D. studentship from the Instituto Nacional de Investigación y Tecnología Agraria y Alimentaria (INIA). NC acknowledges the support of the United Kingdom Food Standards Agency.

Open Access This article is distributed under the terms of the Creative Commons Attribution Noncommercial License which permits any noncommercial use, distribution, and reproduction in any medium, provided the original author(s) and source are credited.

\section{References}

Baert L, Wobus CE, Van Coillie E, Thackray LB, Debevere J, Uyttendaele M (2008) Appl Environ Microbiol 74:543

Baker K, Morris J, McCarthy N et al (2010) An outbreak of norovirus infection linked to oyster consumption at a UK restaurant. J Public Health. doi:10.1093/pubmed/fdq089

Bosch A, Sanchez AG, Abbaszadegan M et al (2011) Food Anal Methods 4:4

Cannon JL, Papafragkou E, Park GW, Osborne J, Jaykus LA, Vinjé J (2006) J Food Prot 69:2761

Costafreda MI, Bosch A, Pintó RM (2006) Appl Environ Microbiol $72: 3846$

Croci L, Dubois E, Cook N, de Medici D, Charlotte Schultz A, China B, Rutjes SA, Hoorfar J, Van der Poel W-HM (2008) Food Anal Methods 1:73

D'Agostino M, Cook N, Rodríguez-Lázaro D et al (2011) Food Environ Virol 3:92

Diez-Valcarce M, Kovac K, Cook N et al (2011) Food Anal Methods (in press)

Dubois E, Hennechart C, Deboosère N (2006) Int J Food Microbiol 108:164

Ethelberg S, Lisby M, Bottiger B et al. (2010) Euro Surveillance 15(6)

Greening GE, Hewitt J (2008) Food Anal Methods 1:109

Grotto I, Huerta M, Balicer RD et al (2004) Infection 32:339

Hall G, Kirk MD, Becker N, Gregory JE et al (2005) Emerg Inf Dis 11:1257

Henshilwood K, Dore WJ, Anderson S, Lees DN (2003) Investigation of Norwalk like virus elimination during depuration using a real time quantitative PCR. In: Villalba A, Romalde JL, Reura B, 
Beiras R (eds) Molluscan shellfish safety. Conselleria de Pesca e Asuntos Maritimos da Xunta de Galicia and Intergovernmental Oceanographic Commission of UNESCO, Galicia, Spain, pp 451-465

Hernroth BE, Conden-Hansson AC, Rehnstam-Holm AS, Girones R, Allard AK (2002) Appl Environ Microbiol 68:4523

Hoorfar J, Malorny B, Abdulmawjood A, Cook N, Wagner M, Fach P (2004) J Clin Microbiol 42:1863

Martínez-Martínez M, Diez-Valcarce M, Hernandez M et al (2011) Food Environ Virol 3:65

Maunula L, Roivainen M, Keränen M et al (2009) Euro Surveillance $14(49)$
Noda M, Fukuda S, Nishio O (2008) Int J Food Microbiol 122:216

Rodríguez-Lázaro D, D'Agostino M, Pla M, Cook N (2004) J Clin Microbiol 42:5832-5836

Rodríguez-Lázaro D, Lewis DA, Ocampo-Sosa AA et al (2006) Appl Environ Microbiol 72:4256

Rodríguez-Lázaro D, Lombard B, Smith H et al (2007) Trends Food Sci Technol 18:306

Scallan E, Hoekstra RM, Angulo FJ et al (2011) Emerg Inf Dis 17:7

Wobus CE, Thackray LB, Virgin HW (2006) J Virol 80:5104

Wyn-Jones A, Carducci A, Cook N, D'Agostino M, Divizia M et al (2011) Water Res 45:1025 